\title{
Offshore Landslides could be favored by Seismic Amplification due to Site Effects
}

\author{
Francoise Courboulex ${ }^{1}$, E. Diego Mercerat ${ }^{2}$, Christophe Larroque ${ }^{1}$, Sébastien Migeon ${ }^{1,3}$, Anne \\ Deschamps ${ }^{1}$, Yann Hello ${ }^{1}$, Marion Baques ${ }^{1}$, Diane Rivet ${ }^{1}$, and David Ambrois ${ }^{1}$ \\ ${ }^{1}$ Université Côte d'Azur,CNRS, IRD, Géoazur, Valbonne, France (courboulex@geoazur.unice.fr) \\ ${ }^{2}$ CEREMA, Equipe Projet MouvGS, Valbonne, France (diego.mercerat@cerema.fr) \\ ${ }^{3}$ Sorbonne Université, Paris, France (migeon@geoazur.unice.fr)
}

In many seismically active areas of the world, earthquakeDinduced landslides commonly account for a significant portion of the total impact of earthquakes. When landslides occur offshore, in coastal areas, they can generate proximal tsunami waves that reach the coastlines in only a few minutes, and can be very dangerous.

The triggering power of earthquakes on landslides is often estimated on seismic wave amplitude (Peak ground acceleration, Arias intensity ...), which is usually computed simply from the magnitude and distance of the earthquake using ground motion prediction equations (GMPEs). In this study we show that the local amplification due to site effect can be very strong offshore, and then should not be neglected.

In order to test and quantify the potential amplification of seismic waves offshore, we installed a broadband seismometer (PRIMA station) near the transition between the continental shelf and the upper continental slope, at a water depth of $18 \mathrm{~m}$, offshore Nice city airport (southeastern France). Situated at the mouth of the Var River, this zone is unstable and prone to landslides. A catastrophic landslide and tsunami already occurred in 1979, causing 10 casualties and large damages.

We analyze the recordings of earthquakes and seismic noise at the PRIMA station by comparing them to nearby inland stations. We find that the seismic waves are strongly amplified at PRIMA at some specific frequencies (with an amplification factor greater than 10 at $0.9 \mathrm{~Hz}$ ). Using geological and geophysical data, we show that the main amplification frequency peak (at $0.9 \mathrm{~Hz}$ ) is due to the velocity contrast between the Pliocene sedimentary layer and fine-grained sediments dated from the Holocene. This offshore site effect could have a crucial impact on the triggering of a submarine landslide by an earthquake in this region.

It is therefore crucial to detect and quantify the seismic amplification effects caused by superficial offshore sediment, in order to take them into account in predictive model. 